\title{
Coagulation Profile in Liver Disease
}

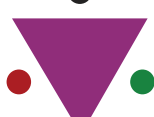

\section{IJCRR}

Section: Healthcare

Sci. Journal Impact

Factor: 6.1 (2018)

ICV: 90.90 (2018)

\author{
Chetali Rupela', Bhavika Vaghela², Hansa Goswami³ \\ ${ }_{1}^{1}{ }^{\text {st }}$ Year Resident, Department of Pathology, B. J. Medical College, Ahmedabad; 'Associate Professor, Department of Pathology, \\ B.J. Medical College, Ahmedabad; 3 Professor and Head of Department, Department of Pathology, B.J. Medical College, Ahmedabad.
}

\section{ABSTRACT}

Background: The liver is the cornerstone of the coagulation system. The physiology of blood coagulation is closely linked to liver function as the liver synthesizes most of the factors of the coagulation cascade and fibrinolytic proteins.

Aims And Objectives: The objective of this study was to evaluate coagulation abnormalities associated with chronic liver diseases and determine the coagulation abnormalities using various coagulation studies PT (Prothrombin time), APTT (activated partial thromboplastin time).

Material and Methods: This study included 50 patients clinically diagnosed with liver disease and who were divided into three categories - cirrhosis, hepatitis, and other liver diseases.

Results: Out of 45 patients with liver disease, 39 were having altered coagulation profile and 28 were having altered biochemical parameters.

Conclusion: We concluded that various abnormalities of coagulation tests vary greatly with different liver disorders, duration of the disorders, and their severity. Prolongation of prothrombin time (PT) and activated partial thromboplastin time (APTT) in advancing liver cirrhosis indicates damage to the liver parenchyma resulting in decreased production of coagulation proteins with increased risk of bleeding tendencies, which can be detected before these ensue.

Key Words: PT, APTT, Liver Disease

\section{INTRODUCTION}

The physiology of blood coagulation is closely linked to liver function as the liver synthesizes most of the factors of the coagulation cascade and fibrinolytic proteins. In addition, the liver is also involved in facilitating the clearance of activated clotting and fibrinolytic factors. ${ }^{(1,2)}$

Patients with liver disease are at a substantially increased risk of thrombosis and hemorrhage. Owing to the substantial overlap in the hemostatic abnormalities observed in the patients with acute infectious or toxic hepatitis, chronic hepatitis, and cirrhosis, the severity of hepatocellular dysfunction is typically more informative than the etiology. Prothrombin time (PT) correlates well with the severity of hepatocellular damage as well as with the occurrence of abnormal bleeding and the overall prognosis. Studies have shown that significant prolongation of prothrombin time and activated partial thromboplastin time (APTT) in the absence of significant hypofibrinogenemia suggests their importance as a reliable marker coagulopathies in chronic liver disease patients. ${ }^{(3,4)}$

\section{MATERIALS AND METHODS}

This study included 3 months data from may 2019 to july 2019 ( 45 patients) clinically diagnosed with liver disease attending medicine clinics in civil hospital, Asarwa in Ahmedabad.

\section{Inclusion Criteria:}

- Primary criterion of inclusion was presence of liver disease including cirrhosis, hepatitis, pseudocyst, liver abscess, and all other liver diseases. All patients of both sexes, age ranging from 20 to 70 years and irrespective of socioeconomic status, were included.

- Exclusion Criteria: Patients with previous history of coagulation disorders or who took any of the following drugs in the previous week were excluded: aspirin or nonsteroidal anti-inflammatory drugs, antihistaminics, penicillin, thiazides, sulfonamides, beta blockers, and anticoagulants.

- Sample Collection and Procedure

\section{Corresponding Author:}

Dr. Bhavika Vaghela, Associate Professor, Department of Pathology, B.J. Medical College, Ahmedabad. E-mail: drbkv1@gmail.com

ISSN: 2231-2196 (Print)

Received: 27.02 .2020
ISSN: $0975-5241$ (Online)

Revised: 05.04 .2020
Accepted: 13.05 .2020 
Blood sample was withdrawn by specially trained phlebotomists from antecubital vein in the forearm by means of vacuttee containing $3.2 \%$ sodium citrate as anticoagulant. While taking the sample, tourniquet was not tied, as it can change the hemoconcentration and results may vary. The ratio of volume of blood to anticoagulant was 9:1. Plasma was obtained following centrifugation of the anticoagulated blood at $3000 \mathrm{rpm}$ for 20 minutes.

Coagulation tests for prothrombin time, activated partial thromboplastin time (APTT), International normalized ratio (INR) were done using fully automated coagulometer. Biochemical parameters for liver disease were done using Fully auto analyzer. Both tests were done maintaining ultimate quality control.

\section{RESULTS}

- The findings for age and sex distribution are compatible with previous studies. The patient's age ranged from 20 to 70 years. The maximum patients were in the age group ranging from 40 to 50 years. Thus, all the patients were above 20 years.

- The patients presented with complaints, such as jaundice, fever, anorexia, fatigue, weight loss, edema of limbs, abdominal pain, and ascites. Among 45 cirrhotic patients, the most common presenting complaints in descending order of frequency were jaundice, ascites, abdominal pain.

\section{PRESENT STUDY DATA}

\begin{tabular}{|c|c|c|c|c|c|}
\hline Age & Sex & $\begin{array}{l}\text { Altered Biochemical pa- } \\
\text { rameters (SGOT/SGPT) }\end{array}$ & $\begin{array}{l}\text { Altered Prothrom- } \\
\text { bin time }\end{array}$ & $\begin{array}{l}\text { Altered Activated } \\
\text { Partial thrombo- } \\
\text { plastin time }\end{array}$ & $\begin{array}{l}\text { Altered Internation- } \\
\text { al normalized ratio } \\
\text { (INR) }\end{array}$ \\
\hline \multirow[t]{2}{*}{ 20-40 year } & 12 male & 7 & 11 & 10 & 11 \\
\hline & 3 female & o & 2 & 1 & 2 \\
\hline \multirow[t]{2}{*}{ 40-6o year } & 22 male & 18 & 20 & 19 & 20 \\
\hline & 2 female & 1 & 1 & 2 & 1 \\
\hline >6o year & 6 male & 2 & 5 & 5 & 5 \\
\hline Total & 45 patients & $28 / 45(62.2 \%)$ & $39 / 45(86.6 \%)$ & $37 / 42(82.2 \%)$ & $39 / 45(86.6 \%)$ \\
\hline
\end{tabular}

The findings for age and sex distribution are compatible with previous studies. Comparison of percentage of cases with altered Coagulation profile in liver disease with previous studies.

\begin{tabular}{lcc} 
Studies & Altered PROTHROMBIN TIME\% & Altered activated partial thromboplastin time \\
& & $71.3 \%$ \\
Sohail Ahmed Siddiqui et al. ${ }^{(5)}$ & $87.7 \%$ & $22.6 \%$ \\
Sylvester Chuks Nwokediuko et al. ${ }^{(6)}$ & $36.6 \%$ & $42 \%$ \\
R C Van Nieuwen huizen et al. ${ }^{(7)}$ & $79 \%$ & $51.7 \%$ \\
Bikha Ram Devrajani et al. ${ }^{(8)}$ & $50.85 \%$ & $82.2 \%$ \\
Present study & $86.6 \%$ & \\
\hline
\end{tabular}

\section{DISCUSSION}

The Prothrombin Time is the test widely accepted means to monitor patients having disorders of specific coagulation factors in the extrinsic and common pathway of coagulation.

In the present study, 86.6\% (39/45) patients had prolonged Prothrombin Time in liver disease. INR (International normalized ratio) was raised in $86.6 \%(39 / 45)$ patients with liver disease. The Activated Partial Thromboplastin Time is the test for intrinsic coagulation pathway. It is especially sensitive for factors XII, IX, XI, XIII, and platelet factor 3 ade- quacies. There were $82.2 \%(37 / 45)$ patients of liver diseases having prolonged Activated Partial Prothrombin Time.

Biochemical parameters for liver disease were raised in 28 patients out of $45(62.2 \%)$. The present study correlates with Sohail Ahmed Siddiqui study in which there was $87.7 \%$ alteration in PT and $71.3 \%$ alteration in APTT in patient with liver disease.

Also it correlates with Sylvester Chuks Nwokediuko study in which there was $36.6 \%$ alteration in PT and $22.6 \%$ alteration in APTT in patient with liver disease. 


\section{CONCLUSIONS}

In this study, we conclude that patients with liver disease have prolonged prothrombin time (PT), activated partial thromboplastin time (APTT) and international normalized ratio (INR). There was significant prolongation of Prothrombin Time in 39 patients out of $45(86.6 \%)$ and Activated Partial Thromboplastin time in 37 patients out of $45(82.2 \%)$ with liver disease.

Study of coagulation profile can help in assessing hepatic cell function and detecting cellular injury. Prolongation of Prothrombin Time and Activated Partial Thromboplastin Time in advancing liver cirrhosis indicates a damage of liver parenchyma resulting in decreased production of coagulation proteins with increased risk of bleeding tendencies, which can be detected before these ensue, by the determination of Prothrombin Time and Activated Partial Thromboplastin Time levels.Thus, preventing patients from landing in life-threatening bleeding complications.

\section{ACKNOWLEDGEMENT}

I would like to thank below mentioned references for their useful suggestions during publication making.

Lastly, I would like to thank patients of B.J medical college, Ahmedabad for support and cooperation.

\section{Financial Support: None}

Conflict of interest: None

\section{REFERENCES}

1. Kaul V, Munoz JS., Coagulopathy of liver disease. Curr Treat Options G Astroenterol 2000 Dec; 3 (6): 433-437.

2. Shah SN, Jansari T., Coagulation profile in liver disease- - study of 100 cases. Gujarat Med J 2014; 69 (1): 37-40.

3. Devrajani BR, Ali Talpur MA, Atta-ur-Rahman A, Ali Shah SZ, Das T, Devrajani T. , Coagulopathies in patients with liver cirrhosis. World Appl Sci J 2012; 17 (1): 01-04.

4. Ahmad Hameed NS, Irfan Khursheed AS, Hamid A, Naveed IA An assessment of coagulation parameters in liver cirrhosis. Biomedica 2006 Jan-Jun; 22: 74-77.

5. Siddiqui SA, Ahmed M, Ghani MH, Memon MA, Mustafa G, Ghori MA: Coagulation abnormalities in patients with chronic liver disease in Pakistan, J Pak Med Assoc, Vol. 61,No. 4,April 2011;363-367.

6. Nwokediuko SC, Ibegbulam OG: Platelet Function and Other Indices of Hemostasis in Chronic Liver Disease, Gastroenterology Research,2010;3(4):167-170

7. Van Nieuwenhuizen RC, Peters M, Lubbers LJ, Trip MD, Tijssen JGP, MulderBJM . Abnormalities in liver function and coagulation profile following the Fontan procedure. Heart 1999;82:40-46.

8. Devrajani BR, Ali Talpur MA, Atta-ur-Rahman A, Ali Shah SZ, Das T, Devrajani T. Coagulopathies in Patients with Liver Cirrhosis, World Applied Sciences Journal, 2012; 17 (1):01-04. 